\title{
Journey to DOR: A Retro Science-Fiction Story on Researching ePrescribing
}

\author{
Valentina Lichtner and Will Venters \\ Information Systems and Innovation Group, Department of Management London School \\ of Economics and Political Science, Houghton Street, WC2A 2AE London, UK \\ $\{$ V.Lichtner, W.Venters\}@lse.ac.uk
}

\begin{abstract}
The core of this paper is a science fiction short story. We are on planet DOR. A group of scientists are working on an experiment, changing underlying mechanisms of transmissions of a colossus machine-a complex system of gears and levers, wires and pipes. Some of its mechanisms are also known as $D$ for doctors, $F$ for pharmacists, $P$ for patients. Observers travel from Earth to study the experiment. Their dilemmas are unaided by their advanced research tools. The story is inspired by research carried out for the evaluation of the forthcoming electronic prescription service in England. Our story is fiction, but it is also a methodological means, a reflexive lever to elaborate and explore our research texts and to question the feasibility, meaning, and impact of researching future technology.
\end{abstract}

Keywords: Future, technology, fiction, systems for electronic transmission of prescriptions, reflexivity, research methods.

\section{Preface}

"I had missed the precious moment when the planet first came into view. Now it was spread out before my eyes; flat, and already immense"

Stanislaw Lem, Solaris, 2003

The core of this paper is a science fiction story. This preface provides the rationale for writing the story, which is then followed by reflections. Some readers may wish to begin by reading the story first (Section 2), then read this preface.

As researchers adopting a social constructionist perspective (Crotty 1998), we seek to produce coherent accounts of our research context through interpretation. We are involved in a project to evaluate the introduction of an electronic prescription service (EPS) in primary care and thus EPS is our research context. Our research project is evaluating EPS at the same time EPS is being developed. EPS compliant software applications are being piloted by a few prescriber (e.g., local doctors surgery) and dispenser (e.g., local pharmacy) sites in England. The challenges of evaluating a national IT project in development are perhaps self-evident: the lack of a definite set of IT systems in place and in use, changing requirements and specifications, and, more generally, shifting ground. The very existence of EPS has been under scrutiny. 
This is made more complex by major changes in the UK National Health Service (NHS) brought about by a newly elected government. Evaluating EPS in the present is thus researching its future, with all its uncertainties, and with very limited space for contributing to steering its course.

Our evaluation project is undertaking detailed observations of, and interviews with, general practitioners, pharmacists, technologists, and various other stakeholders. Such observations and interviews are recorded, transcribed, and entered into our evidence base as research texts. Our epistemology is that of interpretivism-we seek not an objective truth but interpretations of the world of EPS. Yet as researchers we seem to face the gravitational pull of an enlightenment straightjacket, taught since our birth and embedded within our research culture; in our observations we naturally seek objective data, evidence, theory, and conclusions in order to produce research papers. Such papers rely heavily on research texts ${ }^{1}$ produced from literature, project documents, transcripts, conversations, etc. Our papers are open to scrutiny and must be produced in this way; speculation and conjecture can have no place in an evaluation of such a politically charged context.

But what if we were to say that this is important but not sufficient? That as researchers we are always ethnographic, physically embedded within a research context we do not (and cannot) fully grasp? We constantly seek our own interprettations of this context in order to move forward to a future of modest understanding. We visit EPS sites, attend meetings, talk with people, read, reflect, and discuss, and in this we assimilate personal understanding which we struggle to record or express. Further, our interpretations of the EPS implementation include non-verbal clues, tacit perceptions, feelings, moods, incoherent contradictory ideas, and conspiracy theories-all emerging from our experience of the field, but "invalid" for traditional research purposes.

Seeking to find a way to express this kind of "unscientific" understanding of EPS, we welcome the invitation to write a non-traditional paper. ${ }^{2}$ We are thus challenging ourselves by seeking to use fiction and storytelling to reflexively elaborate our tacit knowledge so as to better understand the EPS research context in which we are undertaking research, and through this to improve our traditional research practices.

Fiction and storytelling have an important role in knowledge sharing and reflexive analysis (Denning 2000; Snowden 2000) providing a fluid structure in which knowledge can be expressed and "infusing events with meaning...through the magic of plot" (Gabriel 2000, p. 180). This allows concepts to be remembered, altered, and shared, and allows meaning to diffuse. Similarly, the use of metaphor can help in sharing tacit knowledge (Nonaka 1991). Engagement with stories and the "emotional mind" has been promoted to teach software quality (McBride 2008) and used effecttively to communicate information systems leadership ideas (Austin et al. 2009).

\footnotetext{
${ }^{1}$ By texts, we mean the broad set of evidential material produced in research: transcripts, videos, audio-recordings, written observations, etc.

2 This paper was written in response to the call for papers for the IFIP WG 8.2 conference "Researching the Future" (https://www.wg82.abo.fi/callforpapers.php). The call invited nontraditional approaches and formats, such as science-fiction.
} 
Most vitally, writing allows for a self-reflexive analysis of our understanding, turning the lens inward on the researcher.

While we could further discuss fiction as a research method, we wish to leave center-stage to the fiction itself. We leave to the reader the interpretations of its meanings, in terms of technology for the electronic transmission of medical prescriptions and, more generally, in relation to more-or-less utopian IT systems in healthcare and other sectors, and the role researchers play in their implementation. In concluding this paper, we include some of the comments and reflections to our fiction and provide a set of questions as a starting point to the wider debate on researching the future.

The reader remains free to like or dislike the fiction, agree or disagree with the questions, although we hope this exercise will inspire others to consider writing fiction as part of their methodological arsenal, as a reflective "mode of thought to question and imagine change" (Higgins 2001, p. 5). We should be humble of our inevitable limitations as researchers-and "such humility is essential in creating an environment in which we can learn about the complex systems in which we are embedded and work effectively to create the world we truly desire" (Sterman 2002, p. 527).

\section{Journey to DOR $^{3}$}

The colossal machine was built on a tall thin grid that enabled scientists and observers to work on both sides. Dials, buttons, knobs, and levers were connected by a partially visible intricacy of pipes and wires-a giant radio-like structure without its case. A constant luminous flow was running through the pipes, cylinders and drums moving regularly up and down, while interconnected gears turned one another at various speeds similar to the hour, minute, and second arms of a clock. A scaffold was erected around the machine, so that only the very upper part was accessible. This scaffold gave a bottomless view of the machine below, and its hazy boundaries on the eastern and western sides. It left a vague awareness that other scaffolds might exist at the edges.

A readoscope device connected amongst the pipes produced constant monitoring of inputs and outputs, rates of flows and volumes of stock-state of health, volume of medicines, monetary value. Tiny fluorescent labels identified some of the main controls: $\mathrm{D}$ for doctors, $\mathrm{F}$ for pharmacists, $\mathrm{M}$ for the manufacturers of medicines, $\mathrm{L}$ for money, $\mathrm{P}$ for the patients and those caring for them.

Since the start of the new equinox, scientists had been working on an experiment to introduce a new layer into the apparatus, a new messaging system $E$, based not on pipes of liquid but on electrical impulses. The aim of this transition was to improve the quality of the readoscope results, and the flow and gearings. They had invited the observers to study the experiment and report back to the home planet on its outcome.

\footnotetext{
${ }^{3}$ This text is loosely based on Stanislaw Lem's book Solaris (2003, first published in 1961, translated to English in 1970). Words taken literally from Solaris are highlighted in italics (with page numbers referenced in superscript); Lem's words have been taken out of their original context and placed in this new, completely different story.
} 
The observers were expected to land at any time, their expedition having been delayed by an interstellar ethical storm. E was already in place, all wired-up, and the scientists were anxious to begin.

From the portholes of the spaceship they could see the stars, but this portion of the sky was unfamiliar to ${ }^{2}$ them. Some of them had heard of it, but none of them had visited DOR before. As they got closer to the station, they realized they were landing on a shifting ground, moving at variable speed. They left their cabin at a point of temporary still, but as soon as their feet touched ground they had to take a step forward in order to keep their balance ${ }^{5}$. The expected welcoming party had been cancelled, and the observers were ushered through empty corridors and piles of papers, directly to the machine room. Were the scientists happy to see them?

The observers took a position behind the grid, providing them with a parallel view of all the mechanisms. The scientists were on the other side, with access to the controls. The machine was running its flows and glows, more or less smoothly. A roll of printed paper was spinning out of the readoscope, although little was made of it by those in the room; it simply fell through an opening in the scaffolding. Introductions were made, and the observers were given information materials on the experiment. It was explained to them that $\mathrm{E}$ had already been put in place, to save time, and that the countdown was ready to start. Did they have any questions?

The observers tried to pay attention but their eyes were distracted by the rhythmic move of this glowing apparatus with a life of its own, while their bodies were struggling to stay still on the shifting foot-base. They tried to decipher the mechanisms and their movements-make a map of them in their mind-but they struggled to understand the roles and relationships in the little time available. They decided to focus on E, ask for further details on its inner working and expected benefits.

A transparent thin glass was layered in front of the machine and a projection of $\mathrm{E}$ was superimposed on its mechanisms. The scientists had used this method before quite successfully to illustrate their vision. The starting point was the doctors. E was expected to reduce the load on D; the corresponding gear would run more easily and transmit the effect on F; a temporary increased load on F would be transformed by its inner circuits in tighter controls on $\mathrm{P}$, which at the same time would reduce volumes in $\mathrm{M}$ and pressure on $\mathrm{L}$. The result was expected to be a smoother, more efficient, productive, effective, safer apparatus. The nonlinear equations in the underlying mathematical model had shown that E would also save energy and generally improve the health status of the planet. Minor glitches were expected in the transmission mechanisms, due to inertia-resistance forces, but the scientists were confident that they could be greased and recast as and when necessary.

As the thin glass projection screen retracted, the countdown began - two-hundred and fifty, two-hundred and forty-nine, two-hundred and forty-eight ${ }^{3}$...

Keep a hold on thyself. Be open to see anything. That was the only advice they had been given before boarding. The observers could not think of anything better ${ }^{11}$. During the presentation the scaffold had temporarily paused its shifting, making ground for sound mathematical certitude ${ }^{20}$. But the rolling had slowly started again as soon as the countdown button had been pushed. And the strong starlight coming 
through the portholes cast double shadows ${ }^{27}$ that were hindering the observations. The closer they tried to position themselves to the machine, the more defined were the double contours of their own shadows.

...five, four, three, two point nine, two point eight, two point seven nine, two point seven eight...roll-out. The start button pushed to its full length, the E gear began to slowly turn, steering D to a skewed angle. The transmissions led to a shaking of the whole machine, gear by gear, pipe by pipe, with jolts and scratches. The scientists were reading the readoscope prints, while tightening bolts, loosening belts, oiling pins-mechanics tuning the engine. Speed began to increase, the shuffling of $M$ more rapid. The scientists kept an eye on the observers, as if to read their minds and share enthusiasm for the new venture. The observers glanced back through the grid, almost hypnotized by the rhythmic movement of the machine but unsure what to read in the scientists' faces. The load on D initially increased, as expected, but it was now slowly diminishing; F was taking on the work and modifying its internal circuits to cope with the pressure, a groaning could be heard from that part of the machine, although $\mathrm{P}$ was running as usual, something only the scientists initially noticed. The gear did not seem to modify its behavior the way it should have. The scientists hoped the lack of change in $\mathrm{P}$ would be unnoticeable to the observers. Absence is more difficult to notice than presence, usually, isn't it? That would give them time to fix the malfunction without the need to account for it. They turned to the readoscope. They knew the high volume of data it was producing was of great value.

The observers had prepared for this machine by reading books and papers, but the reality was far more complicated. It was made of more gears and control devices than those explained in the presentation: G.overnment, M.edia, M.ass and P.ersonalized M.edicine, I.T, G.enomics, to name but a few. Changes were appearing on these mechanisms too, but the observers couldn't say if the changing was related to E. How were they going to report in simple terms such an immense, constantly moving, interconnected frenzy of relationships and differences, wires and gears? Each gear in itself was a rich, intricate lace. Their notebooks were filling up with data, text, numbers, sketches as they tried to capture the flow of events and changes in progress. It seemed it was not possible to observe the makeup of the flow itself but clearly it was vital to the operation of the machine. They struggled to see the simplicity the scientists had presented, so enthralled were they by the system's complexity. Perhaps they could have interpreted the machine low-pitched murmuring-the very voice of the machine itself-but they lacked the ears to hear $i t^{126}$. What were they missing, the whole for the gears? Were they focusing on the right layers? Where were the outcomes? More observation work was necessary.

The observers split into groups. The youngest gave themselves more precise tasks, capturing with stopwatches accurate timings of the flow and speed of dials. The most senior took a mimal out of their toolbox, the handheld micromagnetolens that had been applied in many successful projects before to produce real time picotgraphic representations of the combined smaller-and-bigger picture. Gears, pipes, and wires were coming in and out of focus. They tried positioning themselves at a different angle on the shifting platform. If only the ground would stop moving, their work would be much easier. 
As the scientists attempted to repair the reaction mechanisms in $\mathrm{P}$, they saw that $\mathrm{M}$ was having an increased effect on the whole system. They knew there was a risk but they didn't think it would reveal itself so soon. Critical mass-and time-is usually needed before such transformations take place. M's power was increasingly influencing P's behavior now that $\mathrm{E}$ had freed $\mathrm{P}$ from D's control. $\mathrm{P}$ was freely turning to $\mathrm{F}$, generating an exponential growth of $\mathrm{M}$ and corresponding value of $\mathrm{L}$. The scientists tried to intervene on $\mathrm{F}$ by pulling a few levers, but with limited effect. Humming and glowing, the machine had found a new equilibrium, leading to a steady and more fluid growth of $\mathrm{M}$ and a more rapid turning of $\mathrm{P}$, but no signs yet of dramatic change in the health of the nation, nor energy saving. The readoscope printouts were now showing alarming figures of $\mathrm{L}$ and risks for $\mathrm{P}$, but no alarm bells were ringing. The scientists stood back to discuss the variables in the mathematical model. So much for the mathematicians ${ }^{22}$...

The observers were still at work and had not realized the experiment had ended. It seemed changes were still in progress, the machine was still moving. They did notice, though, that the scientists had stopped working on the machine, and they took the opportunity to ask for a few clarifications. Why was E implemented? An easy, straightforward question.

The scientists looked at each other. Apparently the reasons kept changing as the years passed and the project developed, and nobody could recall why it had begun. But they were sure it could be done; it was technically feasible and therefore desirable, a certain technical improvement to the system. In fact, the experiment had demonstrated its success, with the machine moving more fluidly, smoothly-more efficiently.

The observers were on their capsule back to Earth. The night stared them in the face, amorphous, blind, infinite, without frontiers ${ }^{26}$. Traveling gave them a quiet time to write their report. Unfortunately the assiduous efforts of so many years had not resulted in a single indisputable conclusion ${ }^{23}$. They were concerned, but they were back down to Earth. Looking back, they could see that they had flown to DOR not so much to observe the experiment but to acquaint themselves with the machine. With $a$ muffled sigh of resignation, the spaceship expelled its hot air. They were free ${ }^{5}$.

\section{Reflections}

Postmodernist critical theory suggests reflexivity as one way in which researchers can come to terms with their own research circumstances (Gouldner 1970; Calás and Smircich1999). Reflexivity "aims at interpretation, open, language sensitive, identityconscious, historical, political, non-authoritative and textually aware understanding of the subject matter" (Alvesson and Deetz 2000, p. 115). It concerns recognizing the ambivalent relationship of the research texts and evidence to the realities studied (Ashmore 1989) and focuses on the researchers themselves and their experience. Yet a significant constraint to such research practices is the act of writing academic 
papers. The traditional academic paper defines some limits of our writing (Calás and Smircich 1999) and reflexive research should seek alternative writing styles in order to explore the social, historical, and political context of their research (Ashmore 19899), in particular to explore the tacit dimension (Polanyi 1967) of research knowledge which researchers develop in their experience of the field. Perhaps it is the duty of all researchers to come to terms with their own circumstances "before allowing [themselves] the arrogant luxury of disengaged pronouncements on the circumstances of others" (Gouldner 1970, cited in Ashmore 1989, p. 78).

For this reason, we here explore the writing of explicit fiction as a means to elaborate our research "reality" and come to terms with our own research circumstances, drawing on our reflexive understanding, but expressly avoiding "facts" and factual text. As "every reality depends upon the ceaseless reflexive use of a body of knowledge in interaction" (Mehan and Wood 1975, p. 21), so the authoring of this fictional account provided an opportunity to reify and discuss dissatisfaction, concern, and self-critique within EPS and within our EPS evaluation project. Ensuring a focus away from the specifics of the current research project and creating projections and extrapolations-fiction-and especially the sci-fi genre based in the future (McHugh 2001) avoids or reifies ethical and moral concerns so allowing them to be expanded upon but in a less threatening manner (although interestingly we were asked to highlight the disclaimer on the fictional nature of the piece).

Our fictional account is an exercise in futureology; it is inspired by the novel Solaris, by a socio-technical view of the world (Petrakaki and Cornford 2010), and by Peter Checkland's (1981) soft systems thinking. The text is clearly and explicitly not of this world, of this time, of this reality, and thus cannot be seen as a direct representation of our research project. Writing science fiction provided us with the freedom from our own inner academic self-censor. Our story is retro: "a sci-fi vision from the 1950s about a social and political reality now," as one reader described it. The story is about our now, and in particular our problems today in identifying outcomes. It is science fiction, but like all science fiction it is based on the social reality of the present, for why else would it be possible to have retro-sci-fi?

Similarly to writing about the future, researching the future is also always based on the present, or rather the "remembered past" (Lukacs 1994). In a dialectical perspective, "whether studying the past or the future, it is chiefly a matter of looking back, deriving presuppositions from the forms that contain them" (Ollman 2003, p. 122). Just as the hindsight bias skews any research of the past, so the past skews any projection of the future. Look in either direction and the researcher can only see the present.

Solaris was chosen as the basis for our story for its literary strengths and conceptual rather than narrative or plot based structure, and yet this novel can offer us an additional layer for reflection. The book recounts the story of four men in a space station, on a planet, Solaris, a live ocean-like creature with whom Man has been striving to establish contact for centuries. Human theories and models of the ocean fill the space station's library. The ocean resounds like an amorphous, threatening, marvelous, incomprehensible being. It is a psychological story, as the ocean communicates with the four men by presenting them embodiments of their own remorse, hidden in their subconscious. We read it as an epistemological tale: humans are unable to communicate with an entity that they can only know and describe through 
the humans' own theories and nomenclature (our hermeneutic bind, that we are limited by our socially constructed language); the positivism of the Solarian scientists is replaced by the skepticism over their possible achievements and the limitations of the human minds. The ocean is a multiple metaphor-in this case, one of our attempts to research the present/future of EPS, or the observers' attempt to draw outcomes out of the $E$ experiment on the machine of DOR.

When facing the $E$, the observers found themselves in a struggle to know and judge its effect on the system. Technology is embedded in complex socio-technical systems; it is not neutral (Winner 1999); it affects/is affected by the relations that surround it and the expressed intentions for its coming to be, the expressed goals might easily turn into unexpected/unwanted ones (Lem calls this effect the "bifurcation of goals"4). The view of the whole is complex, and made more complex, and both more and less knowable, by an interpretative perspective.

In contrast the scientists in our story had a clearer purpose and a narrower perspective; a pragmatic approach to get the job done. Perhaps we should have called them engineers, as engineers design and build, while in science fiction, especially movies, scientists "being a clearly labeled species of intellectual...are always liable to crack up or go off the deep end" (Sontag 1966, p. 45).

As researchers we find ourselves in dilemmas that leave behind an inability to act. The question is how to overcome them and contribute shaping the technology of our present and future. The difficulty is that what is required is often an answer to transscientific questions, ethical questions not answerable with science (Weinberg 1972), a matter of choice, trade-offs, power, values, accountability. Often we are under considerable pressure to provide simple rational answers-and to be servants of the powerful sponsors of research (Baritz 1960). We must at least attempt to resist.

\section{Postscript}

This fictional piece was inspired by research undertaken to evaluate the electronic prescription service, a Connecting for Health project, part of the NHS National Programme for IT. This paper is a creative reflexive account of researching the future, inspired by the work carried out for the Evaluation of the Electronic Prescription Service in Primary Care. We must explicitly state that this account is not, and cannot be interpreted as, a direct representation of the NHS Electronic Prescription Service or preempt the outcomes of the independent evaluation still in progress.

EPS builds on a set of electronic messaging functionalities newly implemented in existing prescribers' and dispensers' software applications already available on the market (i.e., electronic patient records systems currently used in GP surgeries and pharmacies). The program is being developed in a series of releases: the purpose of EPS-Release 1 was mainly to introduce and test the infrastructure; at the time of writing, EPS-Release 2 compliant systems/functionalities are in the testing phase and getting ready for wider roll-out. Release 2 will introduce electronic signatures and

\footnotetext{
${ }^{4}$ See Stanislaw Lem, "The Official Site," at http://english.lem.pl/works/essays/summatechnologiae/ 108-a-look-inside-summa-technologiae
} 
potentially replace paper prescriptions. More information on EPS can be found on the NHS website. 5

The evaluation of EPS focuses on Release 2. It is an independent research project structured in four different work packages, aimed at assessing different aspects of EPS, including safety of dispensing, changes of work practices in doctors' surgeries and pharmacies, views of patients, and effects on the wider context (e.g., market structures). The different themes are investigated with a mix of qualitative and quantitative research methods, including observations, interviews, participants' selfreported activities, task analysis, stakeholder mapping, etc. The wider EPS context has been the subject of semi-structured face-to-face interviews with representatives of prescribers, dispensers, software suppliers, and other stakeholders. Thirty interviews/meetings were conducted between June 2009 and July 2010. The process of identifying and mapping stakeholders has been described and discussed in Lichtner et al. 2010. Research is still in progress at the time of writing.

\section{Acknowledgments}

The EPS evaluation project is lead by the School of Pharmacy/University of London, in collaboration with the University of Nottingham and the London School of Economics and Political Sciences. More information on CfHEP004 is available on the project website: http://project.epsevaluation.org.uk/.

Investigations on the micro and macro scenarios of EPS have been shared with and supported by the CfHEP004 team, especially (in alphabetical order) Tony Cornford and Dimitra Petrakaki (London School of Economics); Nick Barber, James Davies, and Ralph Hibberd (School of Pharmacy/University of London); and Anthony Avery, Matthew Boyd, Jasmine Harvey, and Justin Waring (Nottingham University). Our thanks to Nick Barber and Tony Cornford for the useful comments on an earlier version of this paper. Special thanks also to the anonymous reviewers, especially for a suggestion on the title. We are indebted to Stanislaw Lem's fictional masterpiece Solaris. Our thanks to Lou Alba for recommending Solaris.

\section{References}

Alvesson, M., Sköldberg, K.: Reflexive Methodology: New Vistas for Qualitative Research. Sage, London (2000)

Alvesson, M., Deetz, S.: Doing Critical Management Research. Sage Publications, Thousand Oaks (2000)

Ashmore, M.: The Reflexive Thesis. University of Chicago Press, Chicago (1989)

Austin, R.D., Nolan, R.L., O'Donnell, S.: The Adventures of an IT Leader. Harvard Business School Press, Boston (2009)

Baritz, L.: Servants of Power. Wesleyan University Press, Middletown (1960)

Calás, M.B., Smircich, L.: Past Postmodernism? Reflections and Tentative Directions. The Academy of Management Review 24, 649-671 (1999)

${ }^{5}$ http://www.connectingforhealth.nhs.uk/systemsandservices/eps 
Checkland, P.: Systems Thinking, Systems Practice. John Wiley and Sons, Chichester (1981)

Crotty, M.: The Foundations of Social Research. Sage, London (1998)

Denning, S.: The Springboard: How Storytelling Ignites Action in Knowledge-Era Organizations. Butterworth-Heinemann, New York (2000)

Gabriel, Y.: Storytelling in Organizations: Facts, Fictions, and Fantasies. Oxford University

Press, Oxford (2000)

Gouldner, A.W.: The Coming Crisis of Western Sociology. Basic Books, New York (1970)

Higgins, M.: Introduction: More Amazing Tales. In: Smith, W., Higgins, M., Parker, M., Lightfoot, G. (eds.) Science Fiction and Organization, pp. 1-12. Routledge, London (2001)

Lem, S.: Solaris. Faber and Faber, London (2003)

Lichtner, V., Petrakaki, D., Hibberd, R., Venters, W., Cornford, A., Barber, N.: Mapping Stakeholders for System Evaluation: The Case of the Electronic Prescription Service in England. In: Safran, C., Reti, S., Marin, H. (eds.) Medinfo 2010-Proceedings of the 13th World Congress on Medical Informatics, Cape Town, South Africa, pp. 1221-1225 (2010)

Lukacs, J.: Historical Consciousness: The Remembered Past. Transaction Publishers, Piscataway (1994)

McBride, N.: Using Performance Ethnography to Explore the Human Aspects of Software quality. Information Technology \& People 21, 91-111 (2008)

McHugh, D.: Give Me Your Mirrorshades: Science Fiction "Methodology" Meets the Social and Organizational Sciences. In: Smith, W., Higgins, M., Parker, M., Lightfoot, G. (eds.) Science Fiction and Organization, pp. 15-30. Routledge, London (2001)

Mehan, H., Wood, H.: The Reality of Eethnomethodology. John Wiley \& Sons, New York (1975)

Nonaka, I.: The Knowledge-Creating Company. Harvard Business Review 69, 96-104 (1991)

Ollman, B.: Dance of the Dialectic: Steps in Marx Method. University of Illinois Press, Urbana (2003)

Petrakaki, D., Cornford, T., Klecun, E.: Sociotechnical Changing in Healthcare. In: Aarts, J., Nohr, C. (eds.) Information Technology in Health Care (ITHC). IOS Press, Aarhus (2010)

Polanyi, M.: The Tacit Dimension. Doubleday, New York (1967)

Snowden, D.: New Wine in Old Wineskins: From Organic to Complex Knowledge Management through the Use of Story. Emergence 2, 50-64 (2000)

Sontag, S.: The Imagination of Disaster. In: Against Interpretation and Other Essays, pp. 209-225.

Farrar, Straus and Giroux, New York (1966)

Sterman, J.: All Models Are Wrong: Reflections on Becoming a Systems Scientist. System Dynamics Review 18, 501-531 (2002)

Weinberg, A.M.: Science and Trans-Science. Minerva 10(2), 209-222 (1972)

Winner, L.: Do Artifacts Have Politics? In: McKenzie, D., Wajcman, J. (eds.) The Social Shaping of Technology, pp. 28-40. Open University Press, London (1999)

\section{About the Authors}

Valentina Lichtner is a postdoctoral research officer at the London School of Economics and Political Sciences. She is interested in adoption and adaptation of IT in healthcare, evaluation of systems, identity and identification technology, human-computer interaction, and patient safety. She is currently conducting research into the introduction of electronic health records and electronic transfer of prescriptions in the English NHS. 
Will Venters is a lecturer in the Department of Management at the London School of Economics and Political Sciences. His research focuses on distributed work practice, and in particular the development of distributed systems to support distributed work. $\mathrm{He}$ is currently conducting research on socio-material understanding of information systems, and agile systems development practices within contexts including Particle Physics at the LHC, UK electronic prescribing, and general practices. 